\title{
Fear of terror and increased job burnout over time: Examining the mediating role of insomnia and the moderating role of work support
}

\author{
SHARON TOKER ${ }^{1 *}$, GREGORY A. LAURENCE ${ }^{2}$ AND YITZHAK FRIED ${ }^{3}$ \\ ${ }^{1}$ Organizational Behavior Program, Faculty of Management, Tel Aviv University, Tel Aviv, Israel \\ ${ }^{2}$ Flint's School of Management, University of Michigan, Flint, Michigan, U.S.A. \\ ${ }^{3}$ Martin J. Whitman School of Management, Syracuse University, Syracuse, New York, U.S.A.
}

\begin{abstract}
Summary
While the prevalence of terrorism has increased substantially, there is a paucity of research on the effects of terrorism on employee behavior at work. Building on conservation of resources (COR) theory, and its extension, the conservation of social resources theory, we close gaps in the literature by investigating the effect of fear of terror on increased job burnout over time, the mediating effect of insomnia, and the moderating effect of supervisor and co-worker support on these relationships. This longitudinal study followed a large sample of Israeli employees $(n=670)$ across three time measurements over 7 years, in a time period characterized by a high number of terror attacks. The results showed fear of terror to be related to elevated job burnout over time, even during a period in which terror attacks were reduced substantially. Further, insomnia mediated the relationship between fear of terror and increased burnout, while co-worker support, but not supervisor support, moderated the relationships between fear of terror and increased insomnia and between increased insomnia and increased burnout. The results further support the notion of loss cycles in COR theory, as well as the importance of social resources, which are the cornerstones of conservation of social resources theory. Copyright (C) 2014 John Wiley \& Sons, Ltd.
\end{abstract}

Keywords: fear of terror; insomnia; burnout; co-worker support; supervisor support

\section{Introduction}

Terrorism has become a fact of modern life. Terrorist attacks are sudden, rare (James, 2011), violent, and destructive events that might target anyone at any time: Recent attacks such as 9/11, the 1993 World Trade Center bombing, the gas attack on the Tokyo subway system in 1995, and the bombing at the Boston Marathon in 2013 have made it obvious that acts of terrorism are not restricted to traditional "hot spots" such as Great Britain during the 1970s-1990s (IRA) or Italy during the 1970s-1980s (Red Brigades). Even before these well-known attacks, researchers acknowledged terrorism as an important form of dysfunctional behavior at the societal level, noting its evolution from small-scale acts targeting specific individuals to indiscriminate violence, killing, and injuring numerous victims (Rapoport, 1984). Clearly, terrorism poses a major threat to society as a whole and to organizations in particular (van Fleet \& van Fleet, 1998), and not solely because of the casualties and material damage it causes: Research suggests that exposure to violence, and specifically terrorism, has a negative impact on mental health (cf., Bleich, Gelkopf, Melamed, \& Solomon, 2006; Fischer, Greitemeyer, Kastenmuller, Jonas, \& Frey, 2006; Galea et al., 2002; Jhangiani, 2009; Norris et al., 2002). In the case of terrorism, the connection may be particularly salient because of the seeming randomness and unjustness of these types of attacks (Pyszczynski, Greenberg, \& Solomon, 1997).

*Correspondence to: Sharon Toker, Organizational Behavior Program, Faculty of Management, Tel Aviv University, Ramat Aviv, Tel Aviv 69978, Israel. E-mail: tokersha@post.tau.ac.il 
Crises such as terrorist attacks have the potential to change organizations and the lives of employees within them (Seeger, Ulmer, Novak, \& Sellnow, 2005), as well as to impact their productivity (Boscarino, Adams, \& Figley, 2006). This suggests that there is an ongoing need to understand the effects of terrorism on organizations and their employees (James, 2011), as well as the role organizations play in helping their employees deal with terror threat (Schouten, Callahan, \& Bryant, 2004). Indeed, numerous studies have examined individuals' reactions to specific, large-scale terrorist events such as those of 9/11 (for a review, see Perlman et al., 2011). However, the long-term effects of smaller-scale terrorist attacks, such as those that occurred pervasively in Israel in the period of the second Palestinian Intifada (uprising) of 2000-2004, remain under-investigated (for an exception, see Hall, Hobfoll, Canetti, Johnson, \& Galea, 2009). Moreover, to date, little research has investigated the effects of terrorism on employees' well-being over time, the mechanisms involved, and the possible coping mechanisms that may mitigate these effects.

We address these gaps in the literature as follows: First, we build on conservation of resources (COR) theory (Hobfoll, 1989) and argue that fear of terror, a proximal outcome of terror, represents worries about losing one's valuable resources (i.e., life and health of both the individual and his or her family). The higher the level of fear of terror, the more likely individuals are to perceive their valuable resources as threatened. This continuous worry depletes their physical, cognitive, and emotional resources and may lead, through continuous loss cycles, to job burnout, years later when terror attacks are no longer prevalent (e.g., Bonanno, Galea, Bucciarelli, \& Vlahov, 2007). Second, we suggest that insomnia, a situation that is characterized as difficulty in falling asleep and/or maintaining sleep (Lavie, 2001), serves as a mechanism through which fear of terror leads to the development of job burnout. Third, using an extension of COR theory-conservation of social resources theory (COSR; Hobfoll, Freedy, Lane, \& Geller, 1990), we propose that support from supervisors and co-workers (a work-related coping mechanism) can mitigate the adverse effects of fear of terror on the development of both insomnia and job burnout. Finally, as the aforementioned effects are expected to develop over time, we studied a large, diverse sample of employed Israelis, who were first surveyed between 2002 and 2004, when terror attacks were a pervasive part of daily life (i.e., in the midst of the second Palestinian Intifada, when there were about 80 terror attacks in 2 years). We followed this sample until 2008.

\section{Hypothesis Development}

\section{The effect of fear of terror on increased job burnout over time}

The COR theory suggests that "individuals strive to obtain, retain and protect those things (resources) they most value, both material and psychosocial" (Hobfoll, 1989: 516). In times of terror, self-preservation (i.e., staying alive), one of individuals' key resources, as well as the lives of family members and friends, is threatened, a state that elicits stress (Hobfoll, Canetti-Nisim, \& Johnson, 2006). In a similar manner, terror management theory, which highlights the importance of self-preservation as people's key motive (Pyszczynski et al., 1997), suggests that terrorist events, being random, unpredictable, and generally directed at non-combatants, bring to the fore the notion that a random event may lead to the death or injury of the self, friends, or family. The "threat to life" associated with exposure to terrorism has been shown, in experimental situations, to contribute to loss of personal resources, high levels of perceived threat, and negative affect (Zeidner, Ben-Zur, \& Reshef-Weil, 2011). Suicide bombings are expected to elicit particularly strong fear of terror because of the irrationality of the bomber causing himself or herself to die, a direct confrontation to mortality salience (Pyszczynski et al., 1997).

Moreover, potential terror victims generally lack knowledge as to when or where a terror event will occur and therefore have limited capability to prepare for it. Such appraisals of uncertainty, or lack of control, can remain active in one's memory over long periods of time (e.g., Lerner \& Keltner, 2001). Thus, even when terror events are not prevalent, as long as people appraise the likelihood of unpredictable, uncontrollable terror attacks as high, 
fear of terror is likely to persist, thus becoming a chronic source of stress. In addition, fear of terror may be elicited through vicarious experiences (e.g., through a close associate's direct exposure to 9/11; North et al., 2011).

When fear of terror is pervasive, it may affect all domains of life, including work domains. COR theory suggests that chronic exposure to resource loss (actual or expected) results in a gradual depletion of individuals' intrinsic energy resources (this depletion is called loss cycles). Furthermore, COR theory places a strong emphasis on downward spirals through which resource loss in one domain (e.g., negative effects of terror on general well-being) may exacerbate resource depletion in other domains (work-related well-being) (Hobfoll, 1989). Indeed, studies have shown that an individual who undergoes gradual resource depletion may develop job burnout, a work-related affective state characterized by emotional exhaustion, physical fatigue, and cognitive weariness (Shirom, 2003; Melamed, Shirom, Toker, Berliner, \& Shapira, 2006). We focus on job burnout as the focal outcome variable because the literature has identified it as an important outcome at work, associated with adverse performance and health-related outcomes (e.g., Maslach, Schaufeli, \& Leiter, 2001; Melamed et al., 2006; Shirom, 2003). We therefore hypothesize the following:

H1: Fear of terror will be positively associated with an increase in job burnout over time.

\section{Insomnia as a mediator of the association between fear of terror and increased job burnout over time}

Although COR suggests that fear of terror may lead to gradual depletion of energy-related resources (e.g., Hobfoll et al., 2006), the mechanisms that drive this depletion are not clear and have not been studied thus far. One possible mechanism is the development of insomnia following exposure to terror. Insomnia is defined as difficulty in falling asleep and/or maintaining sleep (Lavie, 2001) and is a common condition in the general population worldwide (e.g., Ancoli-Israel \& Roth, 1999). Stress has been shown to have a significant effect on insomnia (e.g., Ancoli-Israel \& Roth, 1999; Healey et al., 1981), as have exposure to traumatic events (e.g., the 9/11 terror attacks; DiGrande, Neria, Brackbill, Pulliam, \& Galea, 2010; Schuster et al., 2001) and posttraumatic stress disorder (PTSD; cf., Babson \& Feldner, 2009, and Harvey, Jones, \& Schmidt, 2003, for reviews). Specifically, stressful experiences, including fear of terror, may contribute to autonomic arousal and emotional distress, all of which contribute to increased insomnia (e.g., Bonnet \& Arand, 1997; Harvey, 2002; Lavie, 2001). Fear of terror has also been associated with low grade inflammation (C-reactive protein; Melamed, Shirom, Toker, Berliner, \& Shapira, 2004), which is a related to difficulties in initiating sleep as well as with non-restorative sleep. Finally, fear of terror may also lead to intrusive and disturbing thoughts, namely to rumination, a cognitive state that is characterized by a focus on the past and concerns themes of loss (Smith \& Alloy, 2009). These repetitive thoughts may interfere with individuals' ability to fall asleep, as has been shown in past studies (e.g., Carney, Harris Moss, \& Edinger, 2010).

Insomnia, in turn, depletes individuals' physical energy in addition to their mental resources (e.g., mental ability to concentrate on and accomplish tasks at work), and these factors contribute to the development of job burnout (Armon, Shirom, Shapira, \& Melamed, 2008; Jansson-Fröjmark \& Lindblom, 2010). As suggested by Armon et al. (2008, p. 9), insomnia “...may reduce resources for coping with stress, exacerbate symptoms of mental and physical fatigue among those who are already burned out, and lead to sustained burnout or the development of new cases of burnout." Thus, we suggest that insomnia may serve as a pathway through which fear of terror leads to burnout. As job burnout develops gradually (Houkes, Winants, Twellaar, \& Verdonk, 2011), while insomnia can occur instantly following acute threats (such as terror attacks or terror threats), we expect fear of terror to lead to insomnia and insomnia to job burnout, and not the other way around (cf., Jansson-Fröjmark \& Lindblom, 2010). However, as various additional factors such as high workload or low control may contribute to the development of job burnout (Shirom, 2003), we expect insomnia to partially (and not fully) mediate the association between fear of terror and burnout. Therefore, we hypothesize the following:

$H 2 a$ : Fear of terror will be positively related to increased insomnia over time. 
$H 2 b$ : Insomnia will be positively related to increased job burnout over time.

$H 2 c$ : Insomnia will partially mediate the relationship between fear of terror and job burnout.

\section{The moderating effect of supervisor and co-worker support at work}

In 1990, Hobfoll introduced a theoretical framework that integrates social support into COR theory, calling it COSR (Hobfoll et al., 1990). According to COSR theory, social support is an important resource that enhances one's selfesteem, mastery, and identity and also enables an individual to acquire new resources from others, thus expanding his or her overall resource reservoir. As such, social support may enhance the individual's ability to face various hardships in life by providing instrumental resources and thus potentially stop loss cycles (Hobfoll \& Stokes, 1988). These resource-enhancing effects add to the favorable direct effects of social support on individual and organizational outcomes (e.g., Baruch-Feldman, Brondolo, Ben-Dayan, \& Schwartz, 2002; Uchino, 2006).

We argue that support from supervisors and co-workers should be instrumental in reducing the adverse effects of fear of terror on both insomnia and job burnout among employees. First, social support has favorable effects on employees' physical health, including their longevity (e.g., Shirom, Toker, Alkaly, Jacobson, \& Balicer, 2011), cardiovascular reactivity, and neuroendocrine and hemodynamic responses (e.g., Uchino, Bowen, Carlisle, \& Birmingham, 2012). In particular, social support tends to mitigate the reactivity of the neuroendocrine system to the experience of stress, such that it secretes less cortisol, for example (for a review, see Eisenberger, Taylor, Gable, Hilmert, \& Lieberman, 2007). This suggests that among employees experiencing fear of terror, social support may lower the likelihood of developing insomnia. This argument is supported by Nomura, Nakao, Takeuchi, and Yano (2009), who reported that social support from supervisors and co-workers moderated the effects of job strain (defined as the ratio between workload and control) on insomnia. Second, as suggested by COSR theory (Hobfoll et al., 1990), the instrumental and emotional support employees receive at work allows them to focus, to acquire new resources (such as needed information), and to improve their work performance. It also provides a sense of belongingness and increased security at work and should help employees to better cope with the dual pressures of fear of terror and work demands. Indeed, a recent study indicated that in the wake of 9/11, support from co-workers contributed to employees' emotional recovery (North et al., 2013), and low social support contributed to impaired well-being (for a review, see Perlman et al., 2011). Third, emotional and instrumental support from supervisors and colleagues may also mitigate any potential adverse effects of insomnia on job burnout by allowing individuals with insomnia to perform better, despite their sleep deprivation. For instance, colleagues may cover for a tired employee, and supervisors may reduce employees' workload. This, in turn, can reduce the experience of job burnout (cf., Jansson-Fröjmark \& Lindblom, 2010; Nomura et al., 2009). Thus, we hypothesize the following:

Hypothesis 3a: Work support will moderate the relationship between fear of terror and job burnout, such that fear of terror will be related most strongly to increased job burnout over time when work support is low rather than high.

Hypothesis $3 b$ : Work support will moderate the relationship between fear of terror and insomnia, such that fear of terror will be related most strongly to increased insomnia over time when work support is low rather than high.

Hypothesis 3c: Work support will moderate the relationship between insomnia and job burnout, such that higher insomnia will be related most strongly to increased job burnout over time when work support is low rather than high.

In this longitudinal study, we test the moderating effect of supervisor support separately from that of co-worker support, because it is plausible that employees utilize these sources of support differently. Figure 1 shows a schematic representation of the theoretical model on which our study is based. 


\section{The research Model}

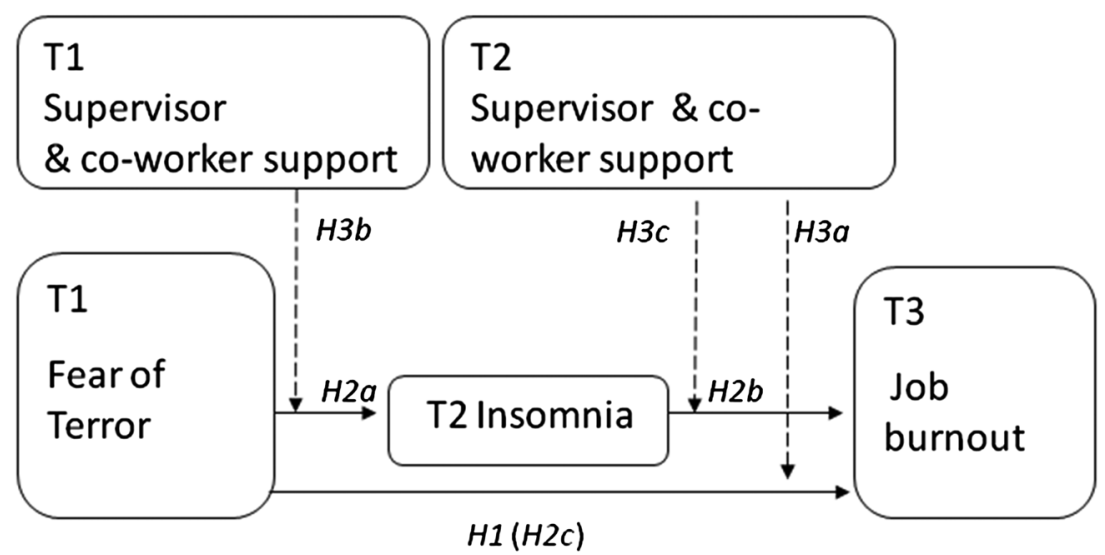

Figure 1. The research model

\section{Methodology}

\section{Sample and data collection}

Data for this study were collected between 2003 and 2008 in an Israeli center for routine health examinations. These examinations were sponsored or subsidized by employers as a fringe benefit, and each employee, independent of health status, was eligible to attend screenings every 18-48 months until retirement. We approached 1161 employed men and women who visited the center for the first time between February 2003 and December 2004 for a routine medical examination and invited them to participate in the study.

Among the employees who were approached, 91 percent agreed to participate in the study, signed an informed consent form, and completed a survey in addition to having their physical examinations. This resulted in an initial sample of 1056 participants (T1). Employees' medical records did not reveal any significant differences between participants and non-participants at T1 in terms of gender or age. Eight hundred ninety-three employees (84.5 percent of the original sample) returned for a second physical examination and survey (T2), averaging about 18 months between visits one and two; 700 employees (66.3 percent of the original sample) returned for a third examination and survey (T3), averaging about 20 months between visits two and three. The 34 percent who did not return for a second or third visit were more likely to be older, male employees, and closer to retirement. We excluded 30 participants who were missing values on any of the study variables. The final sample included 670 employees, and the demographic, occupational, and psychological characteristics of these employees appear in Table 1.

We note that Israel has been a target of terrorism since its inception and that levels of terrorism in the country have risen and fallen at different times in the country's history. Our observations at T1, collected between 2003 and 2004, were taken from individuals who were experiencing exposure to the second Intifada in Israel (2000-2004), during which the rate of terror activity in Israel increased dramatically (Waldman, Carmeli, \& Halevi, 2011). Terror incidents during the years 2000-2004 included over 550 attempted suicide attacks, leading to the deaths of 880 non-combatant civilians. By late 2004, the rate of terrorist attacks had gone down substantially (Ben-Israel, Setter, \& Tishler, 2007). This means that our data enabled us to investigate the degree to which high baseline levels of fear of terror during a period of high terrorist activity affect the development of insomnia and job burnout. Although we do not know with certainty whether individuals in this sample were directly affected by terrorist attacks during the period of data collection (i.e., they were not visiting the hospital for treatment of injuries sustained in a terrorist 
Table 1. Descriptive statistics, Cronbach's alpha, and correlations between study variables.

\begin{tabular}{|c|c|c|c|c|c|c|c|c|}
\hline & Mean & $S D$ & 1 & 2 & 3 & 4 & 5 & 6 \\
\hline 1. $\mathrm{T} 1$ terror & 1.67 & 0.75 & $(.79)$ & & & & & \\
\hline 2. T2 burnout & 1.97 & 0.77 & $.27 * *$ & $(.93)$ & & & & \\
\hline 3. T3 burnout & 1.94 & 0.77 & $.28 * *$ & $.74 * *$ & $(.93)$ & & & \\
\hline 4. T1 insomnia & 2.50 & 0.77 & $.19 * *$ & $.29 * *$ & $.32 * *$ & $(.66)$ & & \\
\hline 5. T2 insomnia & 2.46 & 0.88 & $.21 * *$ & $.35 * *$ & $.37 * *$ & $.78 * *$ & $(.68)$ & \\
\hline 6. T1 manager support & 3.77 & 0.84 & -.01 & $-.22 * *$ & $-.23 * *$ & $-.14 * *$ & $-.12 * *$ & $(.89)$ \\
\hline 7. T2 manager support & 3.88 & 0.87 & -.05 & $-.28 * *$ & $-.24 * *$ & $-.11 * *$ & $-.12 * *$ & $.49 * *$ \\
\hline 8. T1 co-worker support & 3.85 & 0.69 & -.03 & $-.27 * *$ & $-.28 * *$ & $-.18 * *$ & $-.21 * *$ & $.38 * *$ \\
\hline 9. T2 co-worker support & 3.96 & 0.73 & $-.10 * *$ & $-.39 * *$ & $-.37 * *$ & $-.11 * *$ & $-.17 * *$ & $.32 * *$ \\
\hline 10. Age & 46.55 & 9.28 & .01 & $-.10 * *$ & $-.12 * *$ & $.15 * *$ & $.14 * *$ & -.03 \\
\hline 11. Gender & 0.31 & 0.46 & $.29 * *$ & $.21 * *$ & $.21 * *$ & $.17 * *$ & $.14 * *$ & .01 \\
\hline 12. Education years & 15.95 & 2.81 & $-.10 * *$ & -.06 & $-.08 *$ & $-.11 * *$ & $-.10 * *$ & .01 \\
\hline 13. Organizational tenure & 14.61 & 9.84 & $.09 *$ & .00 & -.02 & $.17 * *$ & $.14 * *$ & -.04 \\
\hline 14. Time gap T1-T3 (months) & 40.27 & 15.47 & .06 & .03 & .03 & .00 & -.00 & .01 \\
\hline 15. Terror recency (days) & 31.79 & 34.79 & $-.08 *$ & -.04 & -.02 & -.05 & -.07 & .00 \\
\hline 16. Accumulation of victims & 761.7 & 380.5 & $-.09 *$ & -.05 & .00 & -.05 & -.07 & -.02 \\
\hline
\end{tabular}

Note: $n=670 .{ }^{*} p<.05,{ }^{* *} p<.01$.

attack), it is reasonable to expect, given Israel's relatively small size, that even those not directly impacted by a terrorist event would experience psychological outcomes related to an attack (Moric et al., 2007). We further note that almost all visitors to the medical center were from the central part of Israel, so there was very little geographical dispersion among participants.

\section{Measures}

\section{Independent, dependent, mediator, and moderator variables}

Fear of terror. This variable was measured at T1 by a 3-item scale, adapted from the studies of Gidron, Gal, and Zahavi (1999) and Silver, Holman, McIntosh, Poulin, and Gil-Rivas (2002). This scale used a 5-point Likert-type response pattern anchored by "Never" and "Very Frequently." The three items assessed the degree to which, over the course of the previous month, individuals had experienced (i) fear of being exposed to terrorist attacks, (ii) fear for personal safety, and (iii) tension in crowded places.

Insomnia. This variable was assessed by the Brief Athens Insomnia Scale (Soldatos, Dikeos, \& Paparrigopoulos, 2000) at T1 and T2. This scale consists of five items and uses a 7-point Likert-type response pattern anchored by "Never" and "Always." The items assessed ongoing difficulties with sleep induction and maintenance (e.g., "awakenings during the night" and "early morning awakening").

Supervisor and co-worker support. These two variables were measured at T1 and T2, by two scales adapted from the work of French, Caplan, and van Harrison (1982; see also Melamed, Kushnir, \& Meir, 1991), which indicate, respectively, the level of support that the respondent has received from his or her supervisor and co-workers. Each scale consists of four items and uses a 5-point Likert-type response pattern anchored by "Not True at All" and "Very True." The items assessed the degree to which the respondent consistently perceived his or her supervisor or coworkers (i) as easy to talk to, (ii) as a person who could be relied upon when things got tough, (iii) as a person willing to listen to the respondent, and (iv) as a person who could be expected to go out of his or her way to do things to help the respondent at work. 
Table 1. (Continued)

\begin{tabular}{|c|c|c|c|c|c|c|c|c|}
\hline 7 & 8 & 9 & 10 & 11 & 12 & 13 & 14 & 15 \\
\hline$(.90)$ & & & & & & & & \\
\hline $.33 * *$ & $(.89)$ & & & & & & & \\
\hline $.46^{* *}$ & $.51 * *$ & $(.89)$ & & & & & & \\
\hline-.03 & .03 & -.02 & & & & & & \\
\hline-.05 & .06 & $-.07 *$ & -.00 & & & & & \\
\hline .01 & .04 & .00 & $.11 * *$ & $-.12 * *$ & & & & \\
\hline .02 & .04 & -.00 & $.54 * *$ & $.12 * *$ & $-.09 *$ & & & \\
\hline $.10 * *$ & .03 & $.14 * *$ & $-.22 * *$ & $.12 * *$ & $-.08 *$ & -.03 & & \\
\hline-.00 & .04 & .05 & .01 & .02 & -.01 & .00 & .00 & \\
\hline .00 & .05 & .03 & $-.13^{* *}$ & .01 & -.00 & -.04 & .01 & $.32 * *$ \\
\hline
\end{tabular}

Job burnout. This variable was measured by the Shirom and Melamed Burnout Measure (SMBM; Shirom, 1989, 2003) at T2 and T3. The scale consists of 14 items reflecting physical fatigue (e.g., "I feel physically drained"), cognitive weariness (e.g., "I have difficulty concentrating"), and emotional exhaustion (e.g., "I feel I am unable to be sensitive to the needs of co-workers"), experienced during the last month. All items were scored using a 7-point Likert-type response pattern anchored by "Almost Never" and "Almost Always."

\section{Covariates}

We controlled for several conditions that we believed could have an impact on our variables of interest. These included the following.

Recency of terrorist event. This variable was calculated by computing the number of days that had passed between the most recent terrorist attack and the arrival of the subject for his or her first visit to the medical center where the research surveys were distributed. Information concerning terrorist attacks was gathered from the website of the Ministry of Foreign Affairs of the Government of Israel, which tracks the dates of terrorist bombings and other attacks in Israel and the number of casualties related to those events (http://www.mfa.gov.il/MFA). The Ministry of Foreign Affairs reports a total of 80 terrorist bombings or other attacks in the period during which data were first collected for this study (2003-2004). We controlled for recency because we were interested in fear of terror based on respondents' cumulative experience with terrorist events during the Intifada period, prior to their visit to the medical center. By using recency as a covariate, we aimed to eliminate the effect of an inflation of fear of terrorism that we expected to be associated with temporal proximity to a single terrorist attack prior to survey completion.

Accumulation of victims. This variable was measured as the total number of casualties (injured or dead) of terrorist attacks that had occurred in Israel between the beginning of the second Intifada (the year 2000) and the date of the participant's first visit to the health center. This variable may be positively associated with fear of terror, as higher numbers of casualties might be expected to increase individuals' mortality salience (Pyszczynski et al., 1997). On the other hand, ongoing exposure to terror may also reduce salience of that danger (i.e., if I managed to survive these attacks unharmed, I may be protected). Either way, this variable may confound the results of this study. 
Number of months between the participant's first and third visits to the health center. This variable was controlled for in order to remove any bias on T3 burnout that might be tied simply to the passage of time (Houkes et al., 2011).

Other control variables. Respondents also reported the number of years of education they had completed, their gender (coded 0 for male, 1 for female), their age in years, and their organizational tenure in years. We controlled for years of education, age, and gender, as past studies have found higher insomnia levels among older individuals (e.g., Gellis et al., 2005), among people with lower education (e.g., Petit, Azad, Byszewski, Sarazan, \& Power, 2003), and among women (e.g., Li, Wing, Ho, \& Fong, 2002). Women are also more likely to report higher levels of fear of terror (e.g., Boscarino, Figley, \& Adams, 2006; Nellis, 2009), a fact that can be attributed to a combination of higher levels of terror-related media exposure and women's propensity to more actively seek information from outside sources (Nellis, 2009). We also controlled for organizational tenure, as it may have an impact on employees' levels of social support; for example, newer employees are likely to be less familiar with support sources in their workplace. In addition to these control variables we also examined other possible confounders such as (i) exposure to terrorist events between data collection waves, in other words, the number of terror attacks that occurred between T1 and T2; (ii) anxiety level (based on a 4-item scale from French et al., 1982, in which each item was measured by a 5-point Likert scale), in order to rule out the possibility that fear of terror represents a state of anxiety; (iii) marital status (single/divorced/widower vs. married/in a relationship); (iv) number of children; (v) managerial position (managerial vs. non-managerial); and (vi) neuroticism level, assessed according to eight items from the Big Five Mini-Marker scale (Saucier, 1994). None of these confounders significantly influenced our results. Thus, for purposes of parsimony, we have limited the number of confounders presented in the final analysis.

\section{Statistical analysis}

All predictors were systematically examined to detect outliers or non-normal distributions (i.e., skewness $>2.0$ and kurtosis >5.0); none was detected. The values of the control variables of age, gender, education, tenure, terror recency, and accumulation of victims were based on their values at T1. For each respondent, we also calculated and controlled for the precise T1-T3 time lag in months.

Taken together, the study hypotheses represent a moderated mediation model in which the effect of fear of terror on job burnout is partially mediated by insomnia (indirect effect), contingent on the level of social support (moderation effect). To investigate this moderated mediation model, we applied the procedure suggested by MacKinnon, Fairchild, and Fritz (2007), using the bootstrapping method. The bootstrapping method estimates the sampling distribution of the indirect effect by repeatedly drawing random samples with replacement from the original sample. This enables bootstrapped confidence intervals to be generated in order to test the indirect effect for significance (Shrout \& Bolger, 2002). To test the direct, indirect, and total effects in the mediation model, and to calculate the non-parametric tests of the estimated indirect effects (bootstrapping) and of the moderation effects, we used the PROCESS SPSS macro for moderated mediation analysis (Preacher, Rucker, \& Hayes, 2007). This incorporates procedures to test moderation and mediation hypotheses simultaneously based on a mediator variable (insomnia) and four possible moderators (manager support and co-worker support at T1 and T2),with 1000 bootstrap samples. Fear of terror, insomnia, and manager support and co-worker support were centered prior to the analyses. In the analysis, there were two dependent variables: T2 insomnia (the mediator) and T3 burnout (the outcome). By controlling for $\mathrm{T} 1$ insomnia and $\mathrm{T} 2$ burnout, we were able to represent the $\mathrm{T} 2-\mathrm{T} 1$ change in insomnia and the T3-T2 change in burnout (Twisk, 2003). For exploratory purposes, we repeated the analysis, predicting each of the three facets of burnout (physical exhaustion, cognitive weariness, and emotional exhaustion) as an outcome. Results remained consistent, and therefore, we report the results using the full SMBM score as suggested by Shirom and Melamed (2006). 


\section{Results}

Means, standard deviations, scale reliabilities (Cronbach's $\alpha$ ), and Pearson correlations for the variables in this study are provided in Table 1. Correlation coefficients did not indicate strong multicollinearity, and tests of condition indices and variance inflation factors confirmed that there was no problem with multicollinearity in the data (Belsley, Kuh, \& Welsch, 1980). The bivariate results show that fear of terror is associated with both insomnia and job burnout (correlations range from 0.19 to $0.28, p<.01$ ). Table 1 also indicates that terror recency is negatively associated with fear of terror $(r=-0.08, p<.05)$, such that participants tended to report lower levels of fear of terror when more time had passed between the most recent terror attack and their arrival at the medical center. However, accumulation of victims is also negatively associated with fear of terror $(r=-0.09, p<.05)$, suggesting that higher numbers of victims might reduce the salience of the danger of terrorism. Fear of terror also tended to be higher among women, among participants with fewer years of education, and among people with more years of tenure in the organization $(r=0.29,-0.10,0.09, p<.05$, respectively).

\section{Main effects}

Tables 2 and 3 present the main effects of fear of terror on increases in insomnia and burnout and the main effect of insomnia on increases in job burnout. Fear of terror at T1 was associated with an increase in insomnia from T1 to T2 (Table 2, Model 1, $B(S E)=0.07(0.03), p<.05)$, thus supporting Hypothesis 1 . Similarly, fear of terror at T1 was also associated with an increase in job burnout from T2 to T3 (Table 2, Model 3, $B(S E)=0.08(0.03), p<.01$ ), supporting Hypothesis 2a. Supporting Hypothesis $2 b$, insomnia at T2 was associated with an increase in job burnout from T2 to T3 (Table 3, Model 3, $B(S E)=0.07(0.04), p<.05)$. We also found that co-worker support at T1 was associated with a decrease in insomnia from T1 to T2 (Table 2, Model 2, $B(S E)=-0.10(0.04), p<.01$ ), and

Table 2. The interactive effect of fear of terrorism and supervisor and co-worker support on T2 insomnia.

\begin{tabular}{lrr}
\hline & \multicolumn{1}{c}{ Model 1 } & Model 2 \\
\cline { 2 - 3 } Variable & $B(S E)$ & $B(S E)$ \\
\hline Fear of terror & $0.07(0.03) *$ & $0.07(0.03) *$ \\
T1 insomnia & $0.87(0.03) * *$ & $0.86(0.03) * *$ \\
Terror recency in days & $-0.01(0.00) * *$ & $-0.00(0.00)$ \\
Accumulation of victims & $0.00(0.00)$ & $0.00(0.00)$ \\
T1 supervisor support & $0.01(0.03)$ & $0.01(0.02)$ \\
T1 co-worker support & $-0.11(0.03) * *$ & $-0.10(0.04) * *$ \\
Age & $0.00(0.00)$ & $0.01(0.01)$ \\
Gender & $0.01(0.04)$ & $0.02(0.04)$ \\
Education & $-0.00(0.01)$ & $0.01(0.01)$ \\
Org. tenure & $0.00(0.00)$ & $0.01(0.00) *$ \\
Time gap & $0.00(0.00)$ & $0.00(0.00)$ \\
Fear of terror $*$ T1 supervisor support & & $0.02(0.03)$ \\
Fear of terror $*$ T1 co-worker support & & $-0.10(0.04) * *$ \\
$R^{2}$ & $0.63 * *$ & $0.64 * *$ \\
$\Delta R^{2}$ & & $0.003 *$
\end{tabular}

Note: $n=670 . * p<.05, * * p<.01$

Model 1: Direct effect of fear of terror on T2 insomnia.

Model 2: Adding the interaction effects of fear of terror* T1 social support to Model 1. 
Table 3. The interactive effect of fear of terror, T2 insomnia and supervisor and co-worker support on T3 job burnout.

\begin{tabular}{|c|c|c|c|c|}
\hline & Model 1 & Model 2 & Model 3 & Model 4 \\
\hline Variable & $B(S E)$ & $B(S E)$ & $B(S E)$ & $B(S E)$ \\
\hline \multicolumn{5}{|l|}{ Predictors } \\
\hline Fear of terror & $0.08(0.03)^{* *}$ & $0.08(0.03) * *$ & $0.08(0.03)^{* *}$ & $0.08(0.03)^{* *}$ \\
\hline $\mathrm{T} 2$ job burnout & $0.62(0.03) * *$ & $0.62(0.03)^{* *}$ & $0.61(0.03) * *$ & $0.61(0.03)^{* *}$ \\
\hline $\mathrm{T} 1$ insomnia & $0.11(0.03) * *$ & $0.11(0.03)^{* *}$ & $0.05(0.04)$ & $0.05(0.04)$ \\
\hline Terror recency in days & $-0.01(0.00)$ & $-0.00(0.00)$ & $-0.00(0.00)$ & $0.00(0.00)$ \\
\hline Accumulation of victims & $0.00(0.00)$ & $0.00(0.00)$ & $0.00(0.00)$ & $0.001(0.00)^{*}$ \\
\hline T1 supervisor support & $-0.05(0.03)$ & $-0.05(0.03)$ & $-0.05(0.03)$ & $-0.06(0.03)^{*}$ \\
\hline $\mathrm{T} 2$ supervisor support & $0.01(0.03)$ & $0.03(0.03)$ & $0.01(0.03)$ & $0.02(0.03)$ \\
\hline $\mathrm{T} 1$ co-worker support & $-0.03(0.03)$ & $-0.03(0.03)$ & $-0.02(0.03)$ & $-0.03(0.03)$ \\
\hline T2 co-worker support & $-0.10(0.03)^{* *}$ & $-0.08(0.03)^{*}$ & $-0.10(0.03)^{* *}$ & $-0.09(0.03)^{*}$ \\
\hline \multicolumn{5}{|l|}{ Control variables } \\
\hline Age & $-0.00(0.00)$ & $-0.00(0.00)$ & $-0.00(0.00)$ & $-0.01(0.00)$ \\
\hline Gender & $0.06(0.04)$ & $0.06(0.04)$ & $0.07(0.04)$ & $0.09(0.04)^{*}$ \\
\hline Education & $-0.00(0.01)$ & $-0.01(0.01)$ & $-0.00(0.01)$ & $-0.00(0.01)$ \\
\hline Org. tenure & $-0.00(0.00)$ & $-0.00(0.00)$ & $-0.00(0.00)$ & $-0.00(0.00)$ \\
\hline Time gap & $0.00(0.00)$ & $0.00(0.00)$ & $0.00(0.00)$ & $0.00(0.00)$ \\
\hline \multicolumn{5}{|l|}{ Mediator } \\
\hline T2 insomnia & & & $0.07(0.04)^{*}$ & $0.09(0.04)^{*}$ \\
\hline \multicolumn{5}{|l|}{ Interactions } \\
\hline Fear of terror $* \mathrm{~T} 2$ supervisor support & & $-0.01(0.03)$ & & $0.01(0.03)$ \\
\hline Fear of terror $* \mathrm{~T} 2$ co-worker support & & $0.03(0.04)$ & & $-0.02(0.04)$ \\
\hline $\mathrm{T} 2$ insomnia $* \mathrm{~T} 2$ supervisor support & & & & $0.00(0.03)$ \\
\hline $\mathrm{T} 2$ insomnia * $\mathrm{T} 2$ co-worker support & & & & $-0.08(0.03)^{* *}$ \\
\hline$R^{2}$ & $0.59 * *$ & $0.59 * *$ & $0.60 * *$ & $0.60 * *$ \\
\hline$\Delta R^{2}$ & & 0.00 & $0.01 * *$ & $0.01 * *$ \\
\hline
\end{tabular}

Note: $n=670 . * p<.05, * * p<.01$.

Model 1: Direct effect of fear of terror on burnout when T2 insomnia is not included.

Model 2: Adding the interaction effects of fear of terror* T1 social support to Model 1.

Model 3: Total effect of fear of terror on burnout when T2 insomnia is included.

Model 4: Adding the interaction effects of fear of terror* T1 and T2 social support to Model 3.

similarly, co-worker support at T2 (controlling for co-worker support at T1) predicted a decrease in burnout from T2 to T3 (Table 3, Model 6, B (SE) $=-0.09(0.03), p<.05)$.

With regard to the explained variance of burnout, we focus on the effect of the variables in our study on the variance of burnout at T3, after controlling for the variance explained by burnout at T2 (55 percent). Specifically, the control variables (covariates) explained 1 percent of the variance of burnout, fear of terror explained an additional 1 percent of the changed variance, insomnia added 1.5 percent, co-worker and supervisor support added an additional 1 percent, and the interactive terms added 0.5 percent to the explained variance. Overall, the study variables accounted for 5 percent of the variance in T3 burnout after controlling for T2 burnout.

\section{Moderation effects}

In our analysis, we found that co-worker support, but not supervisor support, moderated the associations between fear of terror and insomnia and between insomnia and burnout, thus partially supporting Hypotheses $3 \mathrm{~b}$ and $3 \mathrm{c}$. T1 co-worker support moderated the association between T1 fear of terror and T2 insomnia (Table 2, Model 2, B 
$(S E)=-0.10(0.04), p<.01)$, thus supporting Hypothesis $3 \mathrm{~b}$, and $\mathrm{T} 2$ co-worker support moderated the association between T2 insomnia and T3 burnout (Table 3, Model 3, $B(S E)=-0.08(0.03), p<.01$ ), thus supporting Hypothesis 3c. We did not find support for Hypothesis 3a, as neither co-worker support nor supervisor support moderated the association between T1 fear of terror and T3 burnout. To further examine the effect of co-worker support on the aforementioned relationships, we graphically illustrated the interaction utilizing a procedure similar to that recommended by Stone and Hollenbeck (1989). Specifically, we plotted three slopes, representing low, medium, and high co-worker support ( $-1 S D$, Mean, $+1 S D$, respectively). As Figures 2 and 3 illustrate, the associations between fear of terror and T2 insomnia, and between T2 insomnia and T3 burnout, are largely invariant for employees with high co-worker support. However, for employees with low and medium co-worker support, higher levels of fear of terror are associated with T2 insomnia (Figure 1), and higher levels of T2 insomnia are associated with higher levels of T3 burnout, such that the less support employees get, the sharper the slope. Further, we conducted simple slopes analyses to examine the significant moderation effect of co-worker support on these associations. As presented in Table 4, the detrimental effects of fear of terror and of insomnia were found mainly among employees with low co-worker support, whereas among employees with high levels of co-worker support, the associations were insignificant (see Figures 2 and 3 for slope $p$-values).

\section{Mediation effects}

Following procedures discussed by MacKinnon et al. (2007), and in accordance with Hypothesis 2c, we confirmed that T2 insomnia partially mediates the association between fear of terror and T3 job burnout. As shown in Table 4, the bootstrapped 95 percent confidence intervals (95 percent CI) around the un-standardized indirect effect of fear of terror do not include zero ( 95 percent $\mathrm{CI}=.003, .035)$. A moderated mediation analysis showed that this mediation is stronger among employees with low or medium levels of co-worker support than among employees with high levels of co-worker support (see Table 5).

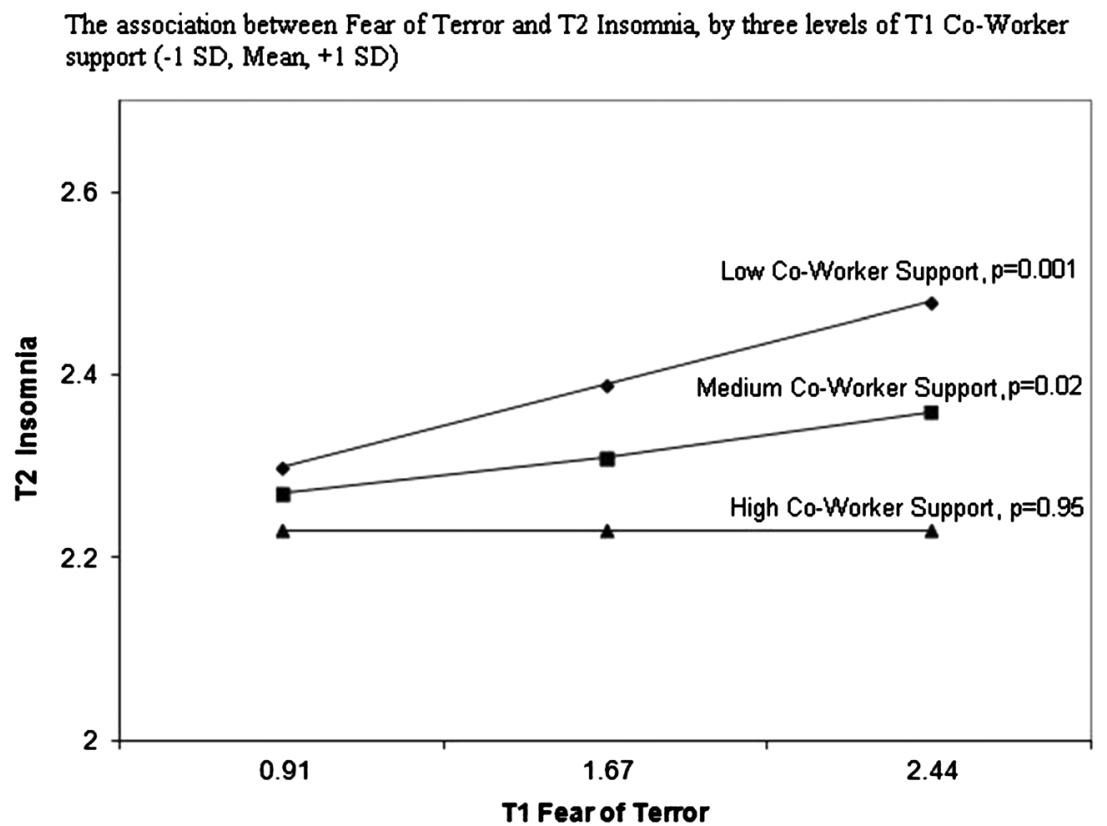

Figure 2. The association between fear of terror and T2 insomnia, by three levels of T1 co-worker support ( $-1 S D$, Mean, $+1 S D)$ 


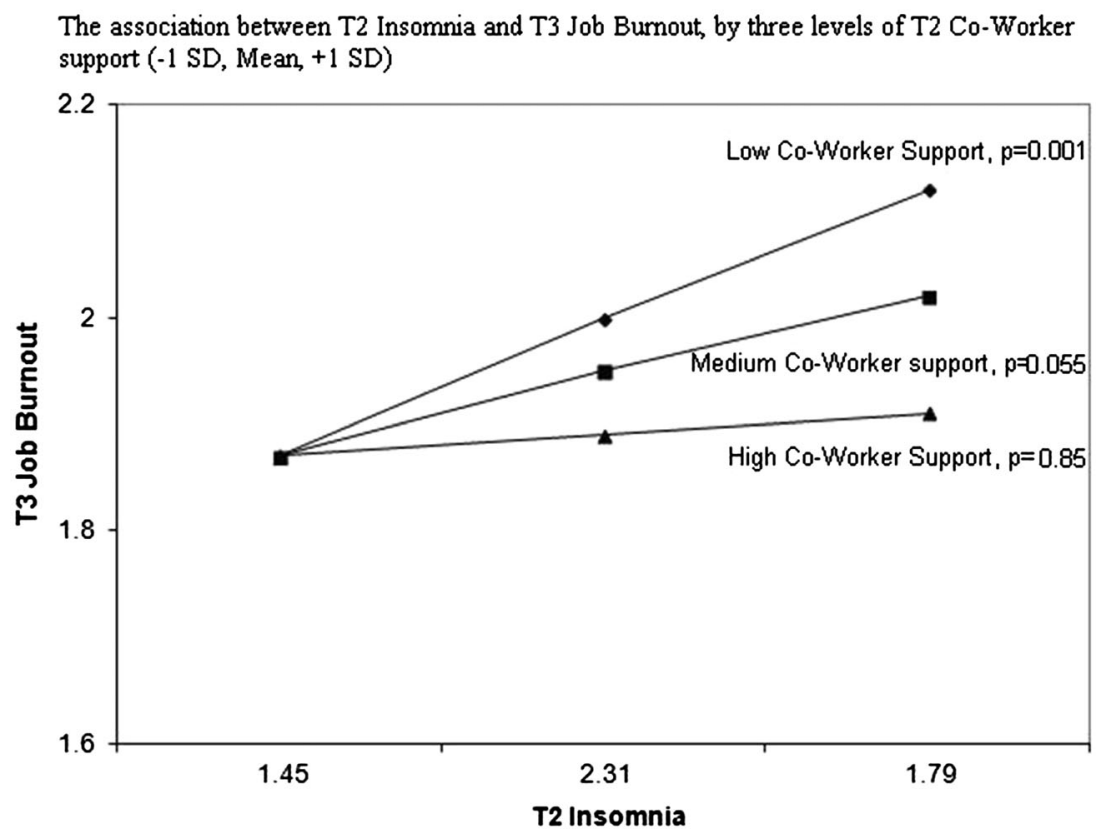

Figure 3. The association T2 insomnia and T3 job burnout, by three levels of T2 co-worker support $(-1 S D$, Mean, $+1 S D)$

Table 4. Simple slope analysis of the significant interactions found in this study.

$B(S E)$

The effect of fear of terror on T2 insomnia under low, medium, and high co-worker support Low support

Medium support

High support

$0.12(0.03) * *$

$0.06(0.03)^{*}$

The effect of $\mathrm{T} 2$ insomnia on $\mathrm{T} 3$ burnout under low, medium, and high co-worker support

Low support

Medium support

$-0.00(0.04)$

High support

$0.13(0.04)^{* *}$

$0.07(0.04)$

$0.01(0.04)$

${ }^{*} \mathrm{p}<0.05 ; * * \mathrm{p}<0.01$

Table 5. Bootstrap results for total, direct, and indirect effect of fear of terror on T3 job burnout through T2 insomnia, moderated by $\mathrm{T} 1$ co-worker support.

$\begin{array}{cccc} & & \text { Bootstrap } & \text { Bootstrap } \\ B & S E & \text { LL 95\% CI } & \text { UL 95\% CI }\end{array}$

Simple mediation analysis

Direct effect

Indirect effect

$0.08 * 03$

Moderated mediation analysis

Indirect* low co-worker support

0.015

Indirect* medium co-worker support

0.012

0.009

0.03

0.003

0.035

Indirect * high co-worker support

0.01

0.001

0.039

0.01

0.003

0.027

${ }^{*} \mathrm{p}<0.05 ; * * \mathrm{p}<0.01$ 


\section{Discussion}

Prior research confirms that exposure to terrorism has detrimental effects on mental health (Norris et al., 2002). However, prior research has largely neglected to explore the effect of terrorism on employee behavior at work and, particularly, on job burnout. Drawing on COR theory, our study is the first that we know of to examine the resource loss cycles that occur over time among employees exposed to terror. Our findings suggest that a spillover process occurs such that a non-work-related stressor (fear of terror) leads to resource loss (insomnia; loss of sleep), and this, in turn, escalates into additional loss of physical, cognitive, and emotional resources (job burnout), especially among employees with low levels of co-worker support. These findings are consistent with the more general terror management theory perspective (Pyszczynski et al., 1997), which supports the notion that death-related stimuli (represented in our study by fear of terror) are related to adverse mental outcomes. We observed these effects in a large sample of employed Israeli men and women who were tracked over 7 years and across three time measurements, both in a time period in which terror incidents were highly prevalent (the period of the Intifada between 2003 and 2004) and in periods when terror was substantially less prevalent (during the follow-up years).

We would like to acknowledge the fact that the effect size of fear of terror on an increase in burnout was relatively small (reaching 1 percent), suggesting that other factors (probably job related factors) play a role in the development of burnout. However, this small effect size is somewhat expected, as burnout is considered to be a chronic affective state, such that the only modest changes in burnout are expected. By controlling for T2 burnout (which highly correlated with T3 burnout; $r=0.74$ ), we inherently limited the possible effect size of all possible predictors. Moreover, the modest effect size seems logical given the context in which this research was undertaken. Context plays an important role in organizational research (cf., Rousseau \& Fried, 2001). As Hobfoll and colleagues (2006) indicated

all Israelis are highly exposed to terrorism, and hence, there really are few people who do not deal with the justified fear of just going to a restaurant, getting on a bus, or waiting until their children are home and safe. On the other hand, less than $1 \%$ of Israelis have experienced a death or injury to a member of their nuclear family, so the severe reactions that are known to occur when people directly encounter terrorism first hand would occur only for a very few individuals in [a] large sample. (pp. 215-216)

Therefore, although the consequences of terrorist attacks are likely to be universal in nature (Salguero, FernandezBerrocal, Iruarrizaga, Cano-Nindel, \& Galea, 2011), and such critical events may lead to adverse consequences such as increased insomnia and burnout, people experiencing fear of terror have not necessarily been directly exposed to terror attacks or personally influenced by them. Moreover, modest levels of explained variance in stressor-outcome relationships are common in longitudinal studies concerning stress (see, e.g., Melamed, Fried, \& Froom, 2001, and an extensive discussion by Zapf, Dorman, \& Frese, 1996). This phenomenon may be driven by several factors, including (i) the large number of factors with the potential to influence the stress-strain relationship, (ii) the potential that some relationships among variables might exist only within particular sub-groups of individuals, and (iii) the socalled healthy worker effect, in which people who are severely impacted by the stressor under consideration may leave the work force (Zapf et al., 1996). Another factor that may be at play here is the specific time effect on the relationships among variables. As in many other studies, the time lags in our data are based on convenience rather than on theory (Zapf et al., 1996). This means that the strength of relationships found in our study may be minimized by collection of data at points in time when the observed relationship is, by nature, less strong.

We also found, in line with COSR theory, that co-worker support moderated the relationships among fear of terror, insomnia, and burnout, as well as the mediation effect of insomnia. Notably, however, supervisor support did not. This observation highlights the importance of distinguishing between specific sources of social support in studies of social resources. This distinction might partially explain why previous studies-which did not make such distinctions-did not find consistent evidence that social support can function as a resource in the face of terrorist threat (see, e.g., Bonanno et al., 2007; Henrich \& Shahar, 2008; Shahar, Cohen, Grogan, Barile, \& Henrich, 2009; 
Vaananen, Vahtera, Pentti, \& Kivimaki, 2005). Additional potential limitations of these previous studies include small and unrepresentative sample sizes, in addition to a focus on singular terrorist events rather than on multiple terror events over time

The observation that supervisor support, unlike co-worker support, does not moderate the relationships in our model may have meaningful implications for organizations. First, it may suggest that the supervisor-subordinate relationship, typically characterized by formality and differences in authority, has less capacity than peer relationships (e.g., with co-workers) to provide individuals with resources that mitigates the effects of fear of terror. Second, as proposed by COSR theory, social support may enhance the self and at the same time provide a major resource reservoir that is otherwise unavailable to the individual. Our findings suggest that a supervisor - a single individual who must divide his or her time across multiple subordinates — does not have the capacity to provide employees with sufficient resources to replenish their reservoirs; rather, employees may need to seek out multiple sources (multiple colleagues) from whom to acquire needed resources. In particular, different co-workers might be able to provide different dimensions of support (e.g., instrumental, informational, and emotional support; see Kaniasty \& Norris, 2004).

These notions coincide with the findings of North and colleagues (2013), who studied workplace responses to 9/11 2 years after the attack occurred, using 12 homogeneous focus groups (three managerial and nine nonmanagerial) of 85 employees of five highly affected organizations. In these companies, co-worker support was found to be an important contributor to mental recovery, yet supervisors "... felt ill prepared to manage the magnitude and the intensity of employees' emotional responses” (p. 101). While North and colleagues' (2013) findings may be attributable to a sample bias, they suggested that supervisors might be incapable of offering adequate support to employees faced with the fear of terror. Thus, it might be worthwhile to investigate whether there are particular domains of supervisor support that may moderate the adverse effect of fear of terror on employee insomnia and job burnout, or whether appropriate training might give supervisors the tools to provide such support.

\section{Study limitations and future research directions}

The present study has several limitations. First, in our study, there was a relatively low mean of the burnout scores. The mean score of the burnout measure (SMBM) was 1.94-1.97, while in other studies (e.g., Holland \& Neimeyer, 2005; Sassi \& Neveu, 2010), it reaches 2.5-3.0. However, this low score does not necessarily impact the generalizability of our results. First, the study was conducted in Israel, where citizens tend to score high on life satisfaction scales, although their rankings on numerous scales, including work-home balance, are low (OECD, 2013). We do not mean to imply that Israelis are not prone to burnout, but it is possible that their burnout ratings may be skewed. Second, the present study does not suggest that a threshold of burnout exists, or that employees who are exposed to fear of terror may reach a specific burnout threshold, but rather that their burnout levels are more likely to increase with time. Indeed, even within this low-scoring sample, burnout was elevated among those who had higher fear of terror. Finally, if this experiment is replicated in other populations, where burnout levels are high, or in organizations where employers do not subsidize routine health screenings, the impact of fear of terror on insomnia and burnout may be even more pronounced.

A second limitation of the study relates to the magnitude and frequency of terror attacks worldwide. Although terror attacks have increased over the past several decades, they are still more common in particular countries. Future studies would benefit from replicating this study in environments (such as in the post-9/11 U.S.A.) in which unpredictable terror incidents occur less often than during the period of the Palestinian uprising.

A third limitation relates to the lack of data that might have enabled us to explore alternative mechanisms involved in the fear of terror-burnout relationship. PTSD is the first mechanism that might be linked to fear of terror and job burnout, as well as to insomnia. Unfortunately, we did not collect information regarding participants' direct exposure to terror attacks, nor did we evaluate PTSD symptoms. However, we suspect that most participants did not experience PTSD, as most civilians are not directly exposed to terror attacks, and mere exposure to terror in the media does not lead to the development of PTSD (American Psychiatric Association, 2013). Moreover, our subjects 
were employed and functioning, which suggests that most had not been seriously traumatized by terror events. A second possible mechanism that was not included in our study is vicarious trauma and guilt that may develop in individuals who experience fear of terror even if they are not exposed to it directly. While our model did not measure survivor guilt, past research does indicate the importance of following collective trauma (Blanchard et al., 2004; Linley, Joseph, Cooper, Harris, \& Meyer, 2003; Wayment, 2004). However, guilt may not necessarily lead to burnout and can actually lead to positive outcomes. For example, Linley et al. (2003) reported that vicarious exposure to the 9/11 attacks resulted in increased faith in the "rightness" of Londoners' world views, and Schuster et al. (2001) suggested that individuals' helping behaviors may increase in the wake of collective trauma. Additionally, Yacoubian and Hacker (1989) found that knowledge about the situation of victims of a distant earthquake elicited feelings of wanting to do something meaningful and effective to help them. Participating in such collective helping behaviors may be instrumental in reducing the same feelings of guilt that spark them (Wayment, 2004). Other possible mechanisms of the link between terror and burnout may include perceptions of potential, or actual, psychosocial resource loss following a terror attack (e.g., Hobfoll et al., 2009), behavioral responses such as cigarette smoking, physical inactivity, or alcohol intake, which past studies have associated with psychological distress (e.g., Hamer, Molloy \& Stamatakis, 2008), and work-related behavioral responses such as working overtime as an escape mechanism.

Future studies might also attempt to shed light on the mechanisms that drive the terror-insomnia relationship. In addition to the psychological and biological mechanisms discussed earlier (Bonnet \& Arand, 1997; Harvey, 2002; Lavie, 2001), it might be of interest to explore the role of specific resource availability (e.g., time). Barnes, Wagner, and Ghumman (2012) have demonstrated that high demands from family and work tend to have a strong impact on sleep reduction. Extending that study to our context, it is conceivable that during periods of terror, people spend more time with their families or at work, for example, in organizations that have suffered financial damage as a result of terror, and therefore have less time for sleep.

Finally, we note that our sample of employees undergoing a periodic health examination may not be representative of the general population, as most of these individuals were educated (mean of 16 years of education), and most of them were not forced to attend these examinations. However, it seems likely that the significant findings obtained here with regard to fear of terror and job burnout would be replicated in samples that include a higher proportion of individuals with lower socioeconomic or occupational status.

\section{Managerial implications}

Our study has some important managerial implications for organizations functioning in an era of terrorism. First, as fear of terror affects employee burnout indirectly by exacerbating insomnia symptoms, organizations can offer workbased interventions aimed at alleviating insomnia (for an example, see Atlantis, Chow, Kirby, \& Singh, 2006). Organizations should also be supportive and protective of their employees in periods of intensive terrorist attacks by facilitating a strong collegial climate in which employees feel attached to the members of their teams or departments. Such a climate can be achieved, for example, through careful selection and placement of people in teams, as well as through incentive systems that promote collaboration and cohesiveness among employees. Organizations can also raise employees' awareness of the importance of turning to colleagues for help during stressful times, and encourage employees to form help-based relationships. Moreover, the long-term effect of fear of terror reported in our study-supported by evidence that effects of fear of terror can occur years after exposure (Moscardino, Scrimin, Capello, \& Altoe, 2010; Zhang et al., 2013)—suggests that organizations should assess the degree to which employees were exposed directly or vicariously to terror attacks and provide access to professional help to employees, even when terror incidents are no longer prevalent. This is especially important because of the blurred borders between the work and home domains, and the potential spillover between them. We note that efforts to provide employees with a supportive social environment as well as with health resources might benefit organizations not only in times of terror but also at any time in which employees experience a threat to their resources, for example, diminished job security in times of economic downturn. 
Managers should further be aware that when employees experience a threat to their important resources (life, health, and well-being), they become stressed and may adopt a "fight or flight" response. Fight responses may be manifested in aggression, abusive behaviors toward others, or work incivility, whereas flight responses may include absenteeism, laggardness, or taking numerous breaks (Johnson \& Swogger, 1990). Understanding the possible terror-related antecedents of such behaviors is a first step toward mitigating them. Finally, governments often calculate the "cost" of terror in terms of the number of casualties as well as the damage to property. We hope that acknowledging the hidden costs of terror (i.e., the impact on workers' well-being and possibly on their performance levels at work) will drive politicians to focus their efforts on promoting peace between rival sides.

\section{Conclusion}

Our research provides valuable information on the long-term effect of fear of terror on job burnout and the important moderating role of co-worker support. This means that organizations can take action to help mitigate the potential harmful effects of terrorism. We hope our findings will serve as the basis for future research to expand our knowledge and understating of the effect of terrorism on organizational outcomes.

\section{Acknowledgment}

This study was conducted at the Tel Aviv Medical Center, as part of the Tel Aviv Medical Center Inflammation Survey (TAMCIS). The authors sincerely acknowledge the invaluable support of Professor Itzhak Shapira, Professor Shlomo Berliner \& Professor Samuel Melamed. This study was supported by grant 788/09 from the Israel Science Foundation (ISF), and by grant 2009/41/A from the Israel National Institute for Health Policy and Health. The authors contributed equally, and their names are listed in reversed alphabetical order.

\section{Author biographies}

Sharon Toker is an Assistant Professor and the Head of the Organizational Behavior Program in the Faculty of Management, Tel Aviv University, Israel. Her research focus is on work-related stressors and their impact on employee's physical and mental health. Dr. Toker recently received the APA-NIOSH Early Career Achievement Award.

Gregory A. Laurence is an Assistant Professor of Management in the University of Michigan, Flint's School of Management. His research concentrates on ownership of work and workspace, specifically investigating how phenomena such as workaholism, workspace personalization and design, and job crafting relate to the experience of stress at work.

Yitzhak Fried is a Professor of Organizational Behavior and Human Resources in the Management Department of Whitman School of Management, Syracuse University, USA. His research focus is on the contribution of context in the areas of cross-culture, work stress, job and office design, motivation, performance appraisal, and diversity. 


\section{References}

Ancoli-Israel, S., \& Roth, T. (1999). Characteristics of insomnia in the United States: Results of the 1991 National Sleep Foundation Survey. Sleep, 22(Suppl. 2), S347-S353.

Atlantis, E., Chow, C. M., Kirby, A., \& Singh, M. A. F. (2006). Worksite intervention effects on sleep quality: A randomized controlled trial. Journal of Occupational Health Psychology, 11(4), 291. DOI: 10.1037/1076-8998.11.4.291

American Psychiatric Association. (2013). Diagnostic and statistical manual of mental disorders: DSM-5. Washington, D.C.: American Psychiatric Association.

Armon, G., Shirom, A., Shapira, I., \& Melamed, S. (2008). On the nature of burnout-insomnia relationships: A prospective study of employed adults. Journal of Psychosomatic Research, 65(1), 5-12. DOI: 10.1016/j.jpsychores.2008.01.012

Babson, K. A. \& Feldner, M. T. (2009). Temporal relations between sleep problems and both traumatic event exposure and PTSD: A critical review. Journal of Anxiety Disorders, 24, 1-15. DOI: 10.1016/j.janxdis.2009.08.002

Barnes, C. M., Wagner, D. T., \& Ghumman, S. (2012). Borrowing from sleep to pay work and family: Expanding time-based conflict to the broader nonwork domain. Personnel Psychology, 65, 789-819. DOI: 10.1111/peps.12002

Baruch-Feldman, C., Brondolo, E., Ben-Dayan, D., \& Schwartz, J. (2002). Sources of social support and burnout, job satisfaction, and productivity. Journal of Occupational Health Psychology, 7(1), 84. DOI: 10.1037/1076-8998.7.1.84

Belsley D. A., Kuh, E., \& Welsch, R. E. (1980). Regression diagnostics. New York: John Wiley \& Sons, Inc. DOI: 10.1002/ 0471725153

Blanchard, E. B., Kuhn, E., Rowell, D. L., Hickling, E. J., Wittrock, D., Rogers, R. L., ...Steckler, D. C. (2004). Studies of the vicarious traumatization of college students by the September $11^{\text {th }}$ attacks: Effects of proximity, exposure, and connectedness. Behaviour Research and Therapy, 42, 191-205. DOI: 10.1016/S0005-7967(03)00118-9

Ben-Israel, I., Setter, O., \& Tishler, A. (2007). R\&D and the war on terrorism: Generalizing the Israeli experience. In A. James (Ed.), Science and technology policies for the anti terrorism era (pp. 51-63). Amsterdam: IOS Press.

Bleich, A., Gelkopf, M., Melamed, Y., \& Solomon, Z. (2006). Mental health and resiliency following 44 months of terrorism: A survey of an Israeli national representative sample. BMC Medicine, 4, 21. DOI: 10.1186/1741-7015-4-21

Bonanno, G. A., Galea, S., Bucciarelli, A., \& Vlahov, D. (2007). What predicts psychological resilience after disaster? The role of demographics, resources, and life stress. Journal of Consulting and Clinical Psychology, 75(5), 671-682. DOI: 10.1037/0022006X.75.5.671

Bonnet, M. H., \& Arand, D. L. (1997). Hyperarousal and insomnia. Sleep Medical Reviews, 2, 97-108. DOI: 10.1016/S10870792(97)90012-5

Boscarino, J. A., Adams, R. E., \& Figley, C. R. (2006). Worker productivity and outpatient service use after the September 11th attacks: Results from the New York City terrorism outcome study. American Journal of Industrial Medicine, 49(8), 670-682. DOI: $10.1002 /$ ajim.20340

Carney, C. E., Harris, A. L., Moss, T. G., \& Edinger, J. D. (2010). Distinguishing rumination from worry in clinical insomnia. Behaviour Research and Therapy, 48(6), 540-546. DOI: 10.1016/j.brat.2010.03.004

DiGrande, L., Neria, Y., Brackbill, R. M., Pulliam, P., \& Galea, S. (2010). Long-term posttraumatic stress symptoms among 3,271 civilian survivors of the September 11, 2001, terrorist attacks on the World Trade Center. American Journal of Epidemiology, 173, 271-281. DOI: 10.1093/aje/kwq372

Eisenberger, N. I., Taylor, S. E., Gable, S. L., Hilmert, C. J., \& Lieberman, M. D. (2007). Neural pathways link social support to attenuated neuroendocrine stress responses, NeuroImage, 35(4), 1601-1612. DOI: 10.1016/j.neuroimage.2007.01.038

Fischer, P., Greitemeyer, T., Kastenmuller, A., Jonas, E., \& Frey, D. (2006). Coping with terrorism: The impact of increased salience of terrorism on mood and self-efficacy of intrinsically religious and nonreligious people. Personality and Social Psychology Bulletin, 32(3), 365-377. DOI: 10.1177/0146167205282738

French, Jr., J. R. P., Caplan, R. D., \& van Harrison, R. (1982). The mechanisms of job stress and strain. Chichester, UK: Wiley.

Galea, S., Ahern, J., Resnick, H., Kilpatrick, D., Bucuvalas, M., Gold, J., \& Vlahov, D. (2002). Psychological sequelae of the September 11 terrorist attacks in New York City. New England Journal of Medicine, 346(13), 982-987. DOI: 10.1056/ NEJMsa013404

Gellis, L. A., Lichstein, K. L., Scarinci, I. C., Durrence, H. H., Taylor, D. J., Bush, A. J., \& Riedel, B. W. (2005). Socioeconomic status and insomnia. Journal of Abnormal Psychology, 114(1), 111. DOI: 10.1037/0021-843X.114.1.111

Gidron, Y., Gal, R., \& Zahavi, S. (1999). Bus commuters' coping strategies and anxiety from terrorism: An example of the Israeli experience. Journal of Traumatic Stress, 12, 185-192. DOI: 10.1023/A:1024762819880

Hall, B. J., Hobfoll, S. E., Canetti, D., Johnson, R. J., \& Galea, S. (2009). The defensive nature of benefit finding during ongoing terrorism: An examination of a national sample of Israeli Jews. Journal of Social and Clinical Psychology, 28, 993-1021. DOI: 10.1521/jscp.2009.28.8.993

Hamer, M., Molloy, G. J., \& Stamatakis, E. (2008). Psychological distress as a risk factor for cardiovascular events: Pathophysiological and behavioral mechanisms. Journal of the American College of Cardiology, 52(25), 2156-2162. DOI: 10.1016/j.jacc.2008.08.057

Harvey, A. G. (2002). A cognitive model of insomnia. Behaviour Research and Therapy, 40(8), 869-893. DOI: 10.1016/S00057967(01)00061-4 
Harvey, A. G., Jones, C., \& Schmidt, D. A. (2003). Sleep and posttraumatic stress disorder: A review. Clinical Psychology Review, 23: 377-407. DOI: 10.1016/S0272-7358(03)00032-1

Healey, E. S., Kales, A., Monroe, L. J., Bixler, E. O., Chamberlin, K., \& Soldatos, C. R. (1981). Onset of insomnia: Role of lifestress events. Psychosomatic Medicine, 43(5), 439-451.

Henrich, C. C., \& Shahar, G. (2008). Social support buffers the effects of terrorism on adolescent depression: Findings from Sderot, Israel. Journal of the American Academy of Child and Adolescent Psychiatry, 47(9), 1073-1076. DOI: 10.1097/ CHI.0b013e31817eed08

Hobfoll, S. E., Freedy, J., Lane, C., \& Geller, P. (1990). Conservation of social resources: Social support resource theory. Journal of Social and Personal Relationships, 7(4), 465-478. DOI: 10.1177/0265407590074004

Hobfoll, S. E. (1989). Conservation of resources: A new attempt at conceptualizing stress. American Psychologist, $44(3), 513-524$. DOI: 10.1037//0003-066X.44.3.513

Hobfoll, S. E., Canetti-Nisim, D., \& Johnson, R. J. (2006). Exposure to terrorism, stress-related mental health symptoms, and defensive coping among Jews and Arabs in Israel. Journal of Consulting and Clinical Psychology, 74(2), 107-218. DOI: 10.1037/0022-006X.74.2.207

Hobfoll, S. E., Palmieri, P. A., Johnson, R. J., Canetti-Nisim, D., Hall, B. J., \& Galea, S. (2009). Trajectories of resilience, resistance, and distress during ongoing terrorism: The case of Jews and Arabs in Israel. Journal of Consulting and Clinical Psychology, 77(1), 138-148. DOI: 10.1037/a0014360

Hobfoll, S. E., \& Stokes, J. P. (1988). The process and mechanism of social support. In S. W. Duck (Ed.), The handbook of research in personal relationships (pp. 497-517). London: Wiley.

Houkes, I., Winants, Y., Twellaar, M., \& Verdonk, P. (2011). Development of burnout over time and the causal order of the three dimensions of burnout among male and female GPs. A three-wave panel study. BMC Public Health, 11(1), 240-252. DOI: 10.1186/1471-2458-11-240

Holland, J. M., \& Neimeyer, R. A. (2005). Reducing the risk of burnout in end-of-life care settings: The role of daily spiritual experiences and training. Palliative \& Supportive Care, 3(03), 173-181. DOI: 10.1017/S1478951505050297

James, K. (2011). Introduction to the special issue: Terrorism, disaster, and organizational science. Journal of Organizational Behavior, 32, 933-937. DOI: 10.1002/job.758

Jansson-Fröjmark, M., \& Lindblom, K. (2010). Is there a bidirectional link between insomnia and burnout? A prospective study in the Swedish workforce. International Journal of Behavioral Medicine, 17, 306-313. DOI: 10.1007/s12529-010-9107-8

Jhangiani, R. (2009). Psychological concomitants of the 11 September 2001 terrorist attacks: A review. Behavioral Sciences of Terrorism and Political Aggression, 2(1), 38-69. DOI: 10.1080/19434470903319474

Johnson, J. W., \& Swogger, G. (1990). Psychological responses to stress: Work and academic inhibition and withdrawal. In J. D. Noshpitz (Ed.), Stressors and the adjustment disorders (pp. 547-558). Oxford: Wiley \& Sons.

Kaniasty, K., \& Norris, F. H. (2004). Social support in the aftermath of disasters, catastrophes, and acts of terrorism: Altruistic, overwhelmed, uncertain, antagonistic, and patriotic communities. Bioterrorism: Psychological and Public Health Interventions, 200-229. DOI: 10.1056/NEJM200506163522421

Lavie, P. (2001). Sleep disturbances in the wake of traumatic events. New England Journal of Medicine, 345(25), $1825-1832$. DOI: $10.1056 /$ NEJMra012893

Lerner, J. S., \& Keltner, D. (2001). Fear, anger, and risk. Journal of Personality and Social Psychology, 81, 146-159. DOI: 10.1037//0022-3514.81.1.146

Li, R. H. Y., Wing, Y. K., Ho, S. C., \& Fong, S. Y. Y. (2002). Gender differences in insomnia-A study in the Hong Kong Chinese population. Journal of Psychosomatic Research 53, 601-609. DOI: 10.1016/S0022-3999(02)00437-3

Linley, P. A., Joseph, S., Cooper, R., Harris, S., \& Meyer, C. (2003). Positive and negative changes following vicarious exposure to the September 11 terrorist attacks. Journal of Traumatic Stress, 16(5), 481-485. DOI: 10.1023/A:10257105282029

MacKinnon, D. P., Fairchild, A. J., \& Fritz, M. S. (2007). Mediation analysis. Annual Review of Psychology, 58, 593-614. DOI: 10.1146/annurev.psych.58.110405.085542

Maslach, C., Schaufeli, W. B., \& Leiter, M. P. (2001). Job burnout. Annual Review of Psychology, 52(1), 397-422. DOI: 10.1146/annurev.psych.52.1.397

Melamed, S., Fried, Y., \& Froom, P. (2001). The interactive effect of chronic exposure to noise and job complexity on changes in blood pressure and job satisfaction: A longitudinal study of industrial employees. Journal of Occupational Health Psychology, 6, 182-195. DOI: 10.1037//1076-8998.6.3.182

Melamed, S., Kushnir, T., \& Meir, E. I. (1991). Attenuating the impact of job demands: Additive and interactive effects of perceived control and social support. Journal of Vocational Behavior, 39, 40-53. DOI: 10.1016/0001-8791(91)90003-5

Melamed, S., Shirom, A., Toker, S., Berliner, S., \& Shapira, I. (2004). Association of fear of terror with low-grade inflammation among apparently healthy employed adults. Psychosomatic Medicine, 66(4), 484-491. DOI: 0033-3174/04/6604-0484

Melamed, S., Shirom, A., Toker, S., Berliner, S., \& Shapira, I. (2006). Burnout and risk of cardiovascular disease: Evidence, possible causal paths, and promising research directions. Psychological Bulletin, 132(3), 327-353. DOI: 10.1037/00332909.132.3.327 
Moscardino, U., Scrimin, S., Capello, F., \& Altoe, G. (2010). Social support, sense of community, collectivistic values, and depressive symptoms in adolescent survivors of the 2004 Besland terrorist attack. Social Sciences and Medicine, 70, 27-34. DOI: $10.1016 /$ j.socscimed.2009.09.035

Moric, M., Buvanendran, A., Lubenow, T. R., Mehta, A., Kroin, J. S., \& Turnan, K. J. (2007). Response of chronic pain patients to terrorism: The role of underlying depression. Pain Medicine, 8(5), 425-432. DOI: 10.1111/j.1526-4637.2006.00177.x

Nellis, A. M. (2009). Gender differences in fear of terrorism. Journal of Contemporary Criminal Justice, 25(3), 322-340. DOI: $10.1177 / 1043986209335012$

Nomura, K., Nakao, M., Takeuchi, T., \& Yano, E. (2009). Associations of insomnia with job strain, control, and support among male Japanese workers. Sleep Medicine, 10(6), 626-629. DOI: 10.1016/j.sleep.2008.06.010

Norris, F. H., Friedman, M. J., Watson, P. J., Byrne, C. M., Diaz, E., \& Kaniasty, K. (2002). 60,000 disaster victims speak out: Part I. An empirical review of the empirical literature, 1981-2001. Psychiatry, 65, 207-239. DOI: 10.1521/ psyc.65.3.207.20173

North, C. S., Pfefferbaum, B., Hong, B. A., Gordon, M. R., Kim, Y. S., Lind, L., \& Pollio, D. E. (2013). Workplace response of companies exposed to the 9/11 World Trade Center attack: A focus-group study. Disasters, 37(1), 101-118. DOI: 10.1111/ j.1467-7717.2012.01295.x

North, C. S., Pollio, D. E., Smith, R. P., King, R. V., Pandya, A., Suris, A. M., Hong, B. A., Dean, D. J., Wallace, N. E., Herman, D. B., Conover, S., Susser, E., Pfefferbaum, B. (2011). Trauma exposure and posttraumatic stress disorder among employees of New York City companies affected by the September 11, 2001 attacks on the World Trade Center. Disaster Medicine and Public Health Preparedness, 5, S205-S213. DOI: 10.1001/dmp.2011.50

OECD. (2013). How's life? 2013: Measuring well-being. How's life? At a glance (pp. 37-70). OECD Publishing: Paris, France. DOI: 10.1787/how_life-2013-6-en

Perlman, S. E., Friedman, S., Galea, S., Nair, H. P., Erős-Sarnyai, M., Stellman, S. D., \& Greene, C. M. (2011). Short-term and medium-term health effects of 9/11. The Lancet, 378(9794), 925-934. DOI: 10.1016/S0140-6736(11)60967-7

Petit, L., Azad, N., Byszewski, A., Sarazan, F. F. A., \& Power, B. (2003). Non-pharmacological management of primary and secondary insomnia among older people: Review of assessment tools and treatments. Age and Ageing, 32, 19-25. DOI: 10.1093/ ageing/32.1.19

Preacher, K. J., Rucker, D. D., \& Hayes, A. F. (2007). Assessing moderated mediation hypotheses: Theory, methods, and prescriptions. Multivariate Behavioral Research, 42, 185-227. DOI: 10.1080/00273170701341316

Pyszczynski, T., Greenberg, J., \& Solomon, S. (1997). Why do we need what we need? A terror management perspective on the roots of human social motivation. Psychological Inquiry, 8(1), 1-20. DOI: 10.1207/s15327965pli0801_1

Rapoport, D. C. (1984). Fear and trembling: Terrorism in three religious traditions. The American Political Science Review, 78(3), 658-677.

Rousseau, D. M., \& Fried, Y. (2001). Location, location, location: Contextualizing organizational research. Journal of Organizational Behavior, 22, 1-13. DOI: 10.1002/job.78

Salguero, J. M., Fernandez-Berrocal, P., Iruarrizaga, I., Cano-Nindel, A. \& Galea, S. (2011). Major depressive disorder following terrorist attacks: A systematic review of prevalence, course and correlates. BMC Psychiatry, 11, 96-106. DOI: 10.1186/1471244X-11-96

Sassi, N., \& Neveu, J. P. (2010). Traduction et validation d'une nouvelle mesure d'épuisement professionnel: Le shirommelamed burnout measure. Canadian Journal of Behavioural Science/Revue canadienne des sciences du comportement, 42 (3), 177. DOI: $10.1037 / \mathrm{a} 0017700$

Saucier, G. (1994). Mini-Markers: A brief version of Goldberg's unipolar Big-Five Markers. Journal of Personality Assessment, 63(3), 506-516. DOI: 10.1207/s15327752jpa6303_8

Schouten, R., Callahan, M. V., \& Bryant, S. (2004). Community response to disaster: The role of the workplace. Harvard Review of Psychiatry, 12(4), 229-237. DOI: 10.1080/10673220490509624

Schuster, M. A., Stein, B. D., Jaycox, L. H., Collins, R. L., Marshall, G. N., Elliott, M. N., ...Berry, S. H. (2001). A national survey of stress reactions after the September 11, 2001 terrorist attacks. New England Journal of Medicine, 345(20), 1507-1512. DOI: 10.1056/NEJM200111153452024

Seeger, M. W., Ulmer, R. R., Novak, J., \& Sellnow, T. L. (2005). Post-crisis discourse and organizational change, failure, and renewal. Journal of Organizational Change Management, 18, 78-95. DOI: 10.1108/09534810510579869

Shahar, G., Cohen, G., Grogan, K. E., Barile, J. P., \& Henrich, C. C. (2009). Terrorism-related perceived stress, adolescent depression, and social support from friends. Pediatrics, 124, 235-240. DOI: 10.1542/peds.2008-2971

Shirom, A. (1989). Burnout in work organizations. In C. L. Cooper \& I. Robertson (Eds.), International review of industrial and organizational psychology (pp. 25-48). New York: Wiley.

Shirom, A. 2003. Job-related burnout. In J. C. Quick, \& L. E. Tetrick (Eds.), Handbook of occupational health psychology (pp. 245-265). Washington, DC: American Psychological Association. DOI: 10.1037/10474-012

Shirom, A., \& Melamed, S. (2006). A comparison of the construct validity of two burnout measures in two groups of professionals. International Journal of Stress Management, 13(2), 176. DOI: 10.1037/1072-5245.13.2.176 
Shirom, A., Toker, S., Alkaly, Y., Jacobson, O., \& Balicer, R. (2011). Work-based predictors of mortality: A 20-year follow-up of healthy employees. Health Psychology, 30(3), 268. DOI: 10.1037/a0023138

Shrout, P. E., \& Bolger, N. (2002). Mediation in experimental and nonexperimental studies: New procedures and recommendations. Psychological Methods, 7, 422-445. DOI: 10.1037//1082-989X.7.4.422

Silver, R., Holman, A., McIntosh, D., Poulin, M., \& Gil-Rivas, V. (2002). Nationwide longitudinal study of psychological response to September 11. Journal of the American Medical Association, 288, 1235-1244. DOI: 10.1001/jama.288.10.1235

Smith, J. M., \& Alloy, L. B. (2009). A roadmap to rumination: A review of the definition, assessment, and conceptualization of this multifaceted construct. Clinical Psychology Review, 29(2), 116-128. DOI: 10.1016/j.cpr.2008.10.003

Soldatos, C. R., Dikeos, D. G., \& Paparrigopoulos, T. J. (2000). Athens Insomnia Scale: Validation of an instrument based on ICD-10 criteria. Journal of Psychosomatic Research, 48, 555-560. DOI: 10.1016/S0022-3999(00)00095-7

Stone, E. F., \& Hollenbeck, J. R. (1989). Clarifying some controversial issues surrounding statistical procedures for detecting moderator variables: Empirical evidence and related matters. Journal of Applied Psychology, 74, 3-10. DOI: 10.1037/0021-9010.74.1.3

Twisk, J. W. R. (2003). Applied longitudinal data analysis of epidemiology. Cambridge: Cambridge University Press. ISBN: 10:0521525802

Uchino, B. N. (2006). Social support and health: A review of physiological processes potentially underlying links to disease outcomes. Journal of Behavioral Medicine, 29(4), 377-387. DOI: 10.1007/s10865-006-9056-5

Uchino, B. N., Bowen, K., Carlisle, M., \& Birmingham, W. (2012). Psychological pathways linking social support to health outcomes: A visit with the "ghosts" of research past, present, and future. Social Science \& Medicine, 74(7), 949-957. DOI: 10.1016/j.socscimed.2011.11.023

Vaananen, A., Vahtera, J., Pentti, J., \& Kivimaki, M. (2005). Sources of social support as determinants of psychiatric morbidity after severe life events: Prospective study of female employees. Journal of Psychosomatic Research, 58, 459-467. DOI: 10.1016/j.jpsychores.2004.10.006

van Fleet, E. W., \& van Fleet, D. D. (1998). Terrorism and the workplace: Concepts and recommendations. In R. W. Griffith, A. O'Leary-Kelly, \& J. Collins (Eds.), Dysfunctional behavior in organizations: Violent and deviant behavior, Vol. 23 (pp. 165-201). Greenwich, CT: JAI Press.

Waldman, D. A., Carmeli, A. \& Halevi, M. Y. (2011). Beyond the red tape: How victims of terrorism perceive and react to organizational responses to their suffering. Journal of Organizational Behavior, 32, 938-954. DOI: 10.1002/job.710

Wayment, H. A. (2004). It could have been me: Vicarious victims and disaster-focused distress. Personality and Social Psychology Bulletin, 30, 515-528. DOI: 10.1177/0146167203261892

Yacoubian, V. V. \& Hacker, F. J. (1989). Reactions to disaster at a distance: The first week after the earthquake in Soviet Armenia. Bulletin of the Menninger Clinic, 53, 331-339.

Zapf, D., Dorman, C., \& Frese, M. (1996). Longitudinal studies in organizational stress research: A review of the literature with reference to methodological issues. Journal of Occupational Health Psychology, 1, 145-169. DOI: 10.1037/10768998.1.2.145

Zeidner, M., Ben-Zur, H., \& Reshef-Weil, S. (2011). Vicarious life threat: An experimental test of conservation of resources (COR) theory. Personality and Individual Differences, 50, 641-645. DOI: 10.1016/j.paid.2010.11.035

Zhang, G., North, C. S., Narayanan, P., Kim, Y. S., Thielman, S., \& Pfefferbaum, B. (2013). The course of postdisaster psychiatric disorders in directly exposed civilians after the US Embassy bombing in Nairobi, Kenya: A follow-up study. Social Psychiatry and Psychiatric Epidemiology, 48(2), 195-203. 